\title{
Dressing Dosage Form
}

National Cancer Institute

\section{Source}

National Cancer Institute. Dressing Dosage Form. NCI Thesaurus. Code C42763.

A substance intended for administration in or on a wound. 